\title{
Brain MRI Measurements at a Term-Equivalent Age and Their Relationship to Neurodevelopmental Outcomes
}

\author{
H.W. Park, H.-K. Yoon, S.B. Han, B.S. Lee, I.Y. Sung, K.S. Kim, and E.A. Kim
}

\begin{abstract}
BACKGROUND AND PURPOSE: An increased prevalence of disabilities is being observed as more preterm infants survive. This study was conducted to evaluate correlations between brain MR imaging measurements taken at a term-equivalent age and neurodevelopmental outcome at 2 years' corrected age among very low-birth-weight infants.
\end{abstract}

MATERIALS AND METHODS: Of the various brain MR imaging measurements obtained at term-equivalent ages, reproducible measurements of the transcerebellar diameter and anteroposterior length of the corpus callosum on sagittal images were compared with neurodevelopmental outcomes evaluated by the Bayley Scales of Infant Development (II) at 2 years' corrected age (mean \pm standard deviation, $16.1 \pm 6.4$ months of age).

RESULTS: Ninety infants were enrolled. The mean gestational age at birth was 27 weeks and the mean birth weight was $805.5 \mathrm{~g}$. A short corpus callosal length was associated with a Mental Developmental Index $<70(P=.047)$ and high-risk or diagnosed cerebral palsy $(P=$ .049). A small transcerebellar diameter was associated with a Psychomotor Developmental Index $<70(P=.003)$, Mental Developmental Index $<70(P=.004)$, and major neurologic disability $(P=.006)$.

CONCLUSIONS: A small transcerebellar diameter and short corpus callosal length on brain MR imaging at a term-equivalent age are related to adverse neurodevelopmental outcomes at a corrected age of 2 years and could be a useful adjunctive tool for counseling parents about future developmental outcomes.

ABBREVIATIONS: $\quad$ AED = antiepileptic drug; $\mathrm{NICU}=$ neonatal intensive care unit; $\mathrm{MDI}=$ Mental Developmental Index; $\mathrm{PDI}=$ Psychomotor Developmental Index; $\mathrm{TCD}=$ transcerebellar diameter

$\mathbf{T}$ he survival rate of preterm infants has increased with the advances in neonatal care in recent decades. However, a higher prevalence of disabilities has also been observed in survivors of preterm birth at infancy and in childhood. ${ }^{1,2}$ Factors such as intraventricular hemorrhage, ${ }^{3}$ hypoxia, prematurity, ${ }^{3-5}$ and neonatal care ${ }^{3,6}$ have been reported to affect the developing brain; the mechanism of injury during the development of the cerebellum and corpus callosum in surviving premature infants may be caused by primary destruction or underdevelopment ${ }^{7}$ and axonal

Received May 15, 2013; accepted after revision June 20.

From the Department of Pediatrics (H.W.P.), Division of Neonatology, Konkuk University Hospital, Konkuk University School of Medicine, Seoul, Korea; and Departments of Radiology (H.-K.Y.), Clinical Epidemiology and Biostatistics (S.B.H.), and Rehabilitation (I.Y.S.) and Department of Pediatrics, Division of Neonatology (B.S.L., K.S.K., E.A.K.), Asan Medical Center Children's Hospital, University of Ulsan, College of Medicine, Seoul, Korea.

Please address correspondence to Ellen Ai-Rhan Kim, MD, PhD, Department of Pediatrics, Division of Neonatology, Asan Medical Center Children's Hospital, University of Ulsan College of Medicine, 88, Olympic-ro 43-gil, Songpa-gu, Seoul 138 736 Korea; e-mail: hwwoman@naver.com

http://dx.doi.org/10.3174/ajnr.A3720 injury, ${ }^{8}$ respectively. These factors in turn result in an altered brain volume or structure that can be seen as a reduced cerebral and/or cerebellar volume, ${ }^{3,9,10}$ subarachnoid space widening, ${ }^{3,6,11}$ corpus callosum thinning, ${ }^{12-14}$ and posthemorrhagic ventricular dilation on brain MR imaging. ${ }^{15}$ These findings have led to reports of various measurements of MR imaging as potential predictors of neurologic outcomes at infancy or in childhood. ${ }^{10,14,16,17}$

We conducted a study in a single neonatal intensive care unit (NICU) to evaluate correlations between brain MR imaging measurements taken at term-equivalent age and the neurodevelopmental outcomes at 2 years' corrected age.

\section{MATERIALS AND METHODS \\ Patients and Perinatal Data}

Infants admitted to the NICU of Asan Medical Center Children's Hospital from January 2001 to December 2010 whose birth weight was $<1 \mathrm{~kg}$ were included in the study cohort. Patients with a birth weight $<1.5 \mathrm{~kg}$ who had clinical indications for brain MR imaging, such as a history of seizure or hypoxic events, or sus- 

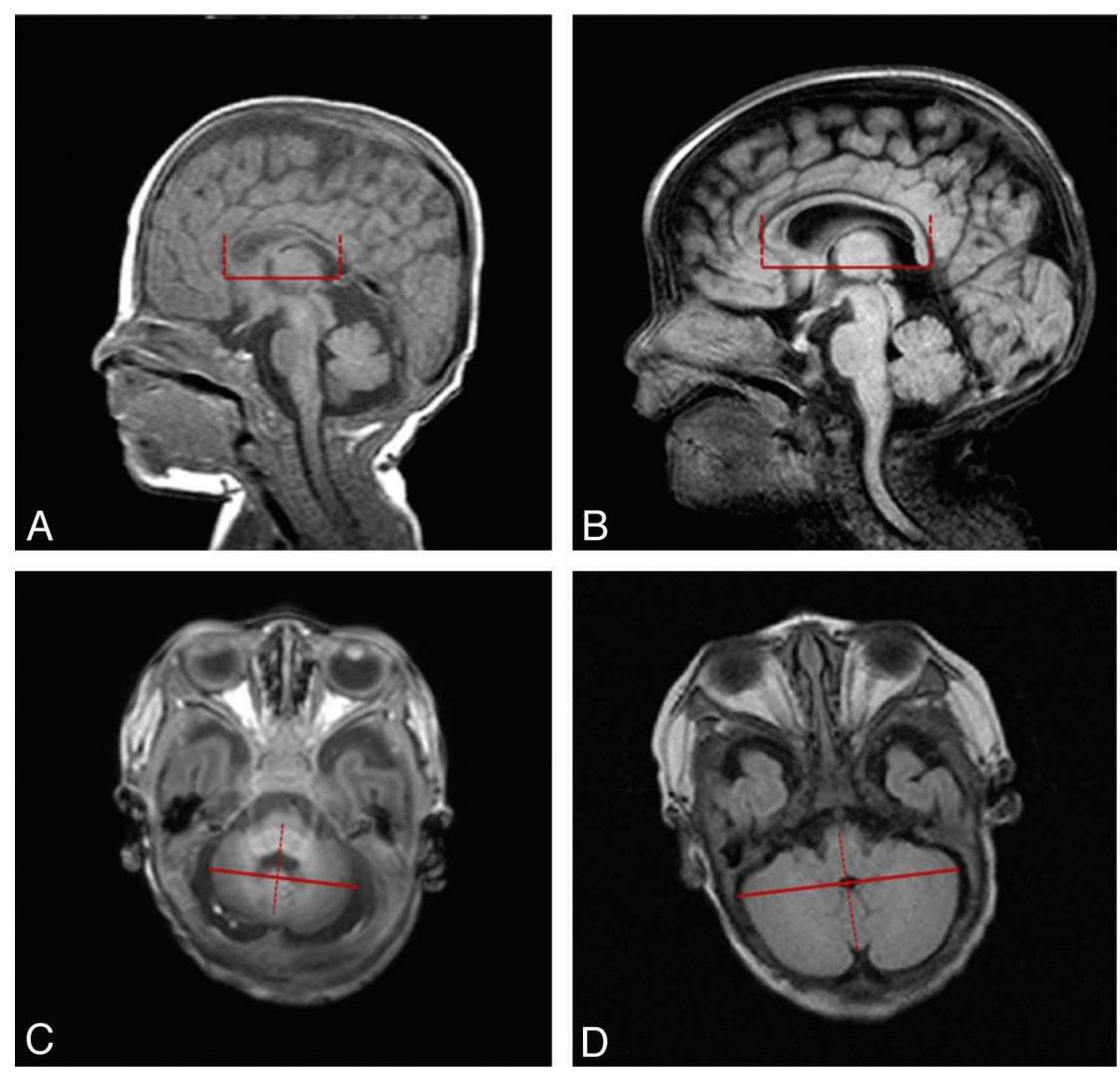

FIG 1. Linear measurements of anteroposterior length of corpus callosum $(A$ and $B)$ and transcerebellar diameter ( $C$ and $D$ ) and intraclass correlation coefficients (ICCs) for interobserver and intraobserver reliability. A, Short anteroposterior length of corpus callosum (34.1 mm); $B$, longer anteroposterior length of corpus callosum ( $44.4 \mathrm{~mm}$ ); $C$, short transcerebellar diameter (36.2 mm); $D$, longer transcerebellar diameter (58.4 mm). pected periventricular leukomalacia by head sonography were also included. The brain MR imaging was obtained at a termequivalent age $\left(37^{+0}\right.$ to $41^{+6}$ weeks). All patients except for 2 (2.2\%) underwent brain MR imaging before NICU discharge.

Exclusion criteria included infants who died before discharge and infants who had severe congenital anomalies such as chromosomal abnormalities or brain anomalies. The clinical charts of the subjects were retrospectively reviewed for various demographic and clinical data: antenatal steroids, ${ }^{18}$ necrotizing enterocolitis defined as modified Bell criteria greater than stage IIa, treatment of symptomatic patent ductus arteriosus ${ }^{19}$ either intravenously with indomethacin or by surgical ligation, laser operation for retinopathy of prematurity, ${ }^{20}$ Papile classification of intraventricular hemorrhage, bronchopulmonary dysplasia (defined as oxygen dependence at 36 weeks' postmenstrual age), and treatment with antiepileptic drugs (AEDs) for electrographic and clinical seizure.

Oxygen requirement was defined as the supplementation of oxygen during hospitalization to maintain the target range of $88-$ $93 \%$ saturation for infants born with a birth weight of $\leq 1.5 \mathrm{~kg}$ with bronchopulmonary dysplasia and $\geq 90 \%$ for other infants.

\section{Brain MR Imaging}

The brain MR imaging was obtained with a $3 \mathrm{~T}$ MR system (3T Achieva Nova Dual; Philips, Best, the Netherlands) around the term-equivalent age before discharge from the NICU. MR images reviewed for this study consisted of spinecho T1-weighted sagittal, T1-weighted axial, and T2-weighted axial images with parameters of 450/10/2 (TR/TE/excitations), 500/10/2, and 3000/80/2, with a field of view of 15 or $18 \mathrm{~cm}$ and a $256 \times$ 256 matrix. Section thickness was $4 \mathrm{~mm}$, with a $1-\mathrm{mm}$ gap. Infants wearing ear protection devices were sedated with choral hydrate $(25-50 \mathrm{mg} / \mathrm{kg}$ orally) or morphine $(0.05 \mathrm{mg} / \mathrm{kg}$ intravenously).

\section{Measurements of MR Imaging}

Brain MR imaging measurements were taken by 2 different neonatologists under the supervision of 1 certified pediatric radiologist. The axial view of the transcerebellar diameter (TCD) and the anteroposterior length of the corpus callosum on sagittal view were measured (Fig 1) with the use of the entirely digital measuring system of the PACS of Asan Medical Center (PetaVision, version 2.1). ${ }^{21}$ The TCD was measured as the longest transverse diameter perpendicular to the cerebellar vermis on the axial view that showed both nasal septum and orbital area, and the corpus callosal length was measured as the anteroposterior length on the midline sagittal image in which the pituitary gland was seen (Fig 1).

\section{Neurologic Outcomes}

The neurodevelopmental outcomes were assessed at 2 years' corrected age with the Bayley Scales of Infant Development II by a certified neonatologist. The Mental Developmental Index (MDI) and the Psychomotor Developmental Index (PDI) were obtained. MDI or PDI scores $<70$ were defined as significantly abnormal. Cerebral palsy was defined as a nonprogressive central nervous system disorder characterized by abnormal posture and abnormal muscular tone in at least 1 extremity; high-risk cerebral palsy was defined as the abnormal tone of extremities and delayed motor development during the first 2 years diagnosed by a certified medical doctor for pediatric rehabilitation. A major neurologic disability was defined as $\geq 1$ of the following findings: $\mathrm{MDI}<70$, PDI $<70$, cerebral palsy, sensorineural hearing loss, and/or seizure disorder.

\section{Data Analysis and Statistics}

Major neurologic disability was the primary outcome variable. A $P$ value of $<.05$ was considered significant. Data were analyzed with the Student $t$ test and logistic regression by use of SPSS 17.0 software (IBM, Armonk, New York). The intraclass correlation coefficients (ICC) for measurement consistency were calculated to analyze the intraobserver and interobserver agreement. In the multivariable regression, risk variables weakly associated with the outcomes in the univariate analysis $(P<.1)$ were used as the candidate variables to identify independent predictors of adverse neurologic outcomes. 
Table 1: General characteristics of the study population

\begin{tabular}{|c|c|}
\hline Variables & Total $(n=90)$ \\
\hline Gestational age, wk & $27^{+1} \pm 2.3$ \\
\hline Birth weight, $g$ & $805.5 \pm 168.2$ \\
\hline Sex, male & $55.6 \%(\mathrm{M}: \mathrm{F}=50: 40)$ \\
\hline Prenatal steroids & $86(95.6 \%)$ \\
\hline PROM & $18(20 \%)$ \\
\hline Delivery mode, C-section & $67(74.4 \%)$ \\
\hline Presence of IUGR & $36(40 \%)$ \\
\hline Apgar score, $1 \mathrm{~min}$ & $4 \pm 1.9$ \\
\hline Apgar score, $5 \mathrm{~min}$ & $7 \pm 1.4$ \\
\hline Duration of ventilator care, $\mathrm{d}$ & $27 \pm 25.3$ \\
\hline Presence of $\mathrm{BPD}, \mathrm{O}_{2}$ at $36 \mathrm{wk}$ & $22(24.4 \%)$ \\
\hline Postnatal steroids & $45(50 \%)$ \\
\hline History of sepsis, culture-proven & $28(31.1 \%)$ \\
\hline Peak level of CRP, mg/dL & $2.83 \pm 4.84$ \\
\hline NEC & $8(8.9 \%)$ \\
\hline ROP & $48(53.3 \%)$ \\
\hline IVH grade $3-4$ & $9(10 \%)$ \\
\hline Laser operation for ROP & $21(23.3 \%)$ \\
\hline AED medication & $8(8.9 \%)$ \\
\hline
\end{tabular}

Note:-Data are reported as number (\%) or as mean \pm standard deviation. CRP indicates C-reactive protein; IUGR, intrauterine growth restriction; IVH, intraventricular hemorrhage; NEC, necrotizing enterocolitis; PROM, premature rupture of membrane; ROP, retinopathy of prematurity; BPD, bronchopulmonary dysplasia.

\section{RESULTS}

\section{General Characteristics of Patients}

The general characteristics of the 90 infants are shown in Table 1. Of the 90 patients, 80 (88.9\%) were extremely low-birth weight infants.

\section{Perinatal Factors Associated with Adverse Neurologic Outcomes}

In total, 15 of 90 infants (16.7\%) and 24 of 90 (26.7\%) infants showed MDI and PDI values $<70$, respectively. Another 8 patients $(8.9 \%)$ were diagnosed with cerebral palsy, and $33(36.7 \%)$ showed major neurologic disabilities. Risk variables found to be significantly correlated with the outcomes in the univariate analysis were entered into multivariate analysis: AED medication $(\mathrm{OR}, 7.687 ; \mathrm{P}=.023)$ and the duration of $\mathrm{O}_{2}$ requirement $(\mathrm{OR}$, $10.014 ; P=.055)$ were associated with a PDI $<70$; the duration of $\mathrm{O}_{2}$ requirement $(\mathrm{OR}, 10.022 ; \mathrm{P}=.009)$ and a history of sepsis $(\mathrm{OR}$, 3.723; $P=.044)$ were associated with an MDI $<70$. The use of prenatal steroids (OR, $0.065 ; P=.028$ ) showed a protective effect on cognitive function (Table 2). The factors associated with a major neurologic disability included the use of AED medication (OR, 6.958; $P=.025)$ and a history of sepsis (OR, 2.508; $P=.058$ ) (Table 2).

\section{Association between Measurements of MR Imaging and Adverse Neurologic Outcomes}

The linear measurement of the TCD and the anteroposterior length of the corpus callosum on MR imaging showed satisfactory ICCs for interobserver and intraobserver reliabilities (Fig 1). A short TCD was associated with poor motor and cognitive function, as indicated by a $\mathrm{PDI}<70$ (OR, 0.780; $P=.003)$, MDI $<70(\mathrm{OR}, 0.785 ; P=.004)$, and major neurologic disability (OR, $0.815 ; P=.006)$. A short anteroposterior length of the corpus callosum was associated with an MDI $<70$ (OR, 0.876; $P=.047$ ) and high-risk or diagnosed cerebral palsy (OR, 0.915; $P=.049)$ (Table 3).

\section{Perinatal Factors Associated with TCD and Length of Corpus Callosum on Multivariate Analysis}

Among several perinatal factors, birth weight (OR 0.005, $P=$ .043 ), presence of bronchopulmonary dysplasia (OR, -2.358 ; $P=.007)$, use of AED medication (OR, $-3.347 ; P=.010)$, and a history of sepsis $(\mathrm{OR},-1.642 ; P=.034)$ were associated with a short TCD. The factors associated with corpus callosal length included a small head circumference at the time of the MR imaging (OR, 3.947; $P<.001)$, the use of prenatal steroids (OR, 10.141; $P=$ $.002)$, and AED medication $(\mathrm{OR},-8.215 ; P<.001)$ (Table 4$)$.

\section{DISCUSSION}

Many neonatologists counsel parents of very low-birth-weight infants about the long-term prognosis with the use of known antenatal $^{22,23}$ and postnatal risk factors ${ }^{3,4,24,25}$ associated with neurodevelopmental outcomes. In-depth studies ${ }^{26-28}$ are in progress to better predict neurodevelopmental outcomes in this vulnerable population. The objective of this study was to evaluate correlations between brain MR imaging measurements taken at termequivalent age before discharge from the NICU and the neurodevelopmental outcome at 2 years' corrected age among very low-birth-weight infants. We used the PACS system of the Asan Medical Center, which has been described in detail in Im et al ${ }^{21}$ to measure the different brain parameters. Other reports ${ }^{29-31}$ have shown the usefulness of this system, emphasizing its reproducibility and reliability as well as the convenient access to images. Unlike the other $9 \mathrm{MR}$ imaging parameters that we also measured (data not shown), which included ventricle width, biparietal diameter, bifrontal diameter, subarachnoid space widening (axial and sagittal images), and corpus callosal thickness. Among them, only the TCD and corpus callosal length were found to have acceptable intraclass and interclass correlation coefficients for consistency (Fig 1). The measurement of TCD on the coronal plane was used before by Nguyen The Tich et al, ${ }^{16}$ but we measured TCD on the axial plane, which also could be applied on an axial CT image.

The rapid growth of the cerebellum that occurs from 28-40 weeks of gestation can be impeded by premature birth. ${ }^{7,32,33}$ Here, a smaller TCD, indicative of neuronal loss or impaired neuronal differentiation with a reduction in dendritic and axonal development that may be independent of immaturity, ${ }^{3}$ was associated with poor cognitive and psychomotor function. These results concur with those of the report of Tich et $\mathrm{al}^{34}$ in preterm infants born at a gestational age $<30$ weeks or a weight of $<1.25$ $\mathrm{kg}$. The cerebellar injury, mainly occurring in the external granular layer, possibly related to a disturbance of cerebellar growth caused by hemosiderin on the cerebellar surface or postnatal factors such as hypoxia-ischemia, infection, and steroids as well as direct cerebellar destructive injury. ${ }^{7,8}$ Impaired neuronal connection between cerebrum and cerebellum as a remote effect can also contribute to cerebellar underdevelopment. ${ }^{7,8}$

We used phenobarbital as a primary medication in neonatal seizure when both clinical and electrical evidence of seizures was evident. Both the seizures and the AED medication may cause cerebellar atrophy - either synergistically ${ }^{35}$ or independently ${ }^{36}$ during the development of the cerebellum. Abnormalities of the cerebellum in mice after exposure to phenobarbital, such as a decrease in the number of Purkinje $\mathrm{e}^{37}$ and granular cells, ${ }^{33}$ without 
Table 2: Relationship between perinatal factors and adverse neurologic outcomes determined by multivariate logistic regression analysis

\begin{tabular}{|c|c|c|c|}
\hline Neurologic Outcomes & Perinatal Factors & OR $(95 \% \mathrm{Cl})$ & $P$ Value \\
\hline \multirow[t]{2}{*}{ PDI $<70$} & Duration of $\mathrm{O}_{2}$ requirement & $10.01(0.999-10.028)$ & .055 \\
\hline & AED medication & $7.69(1.329-44.476)$ & .228 \\
\hline \multirow[t]{3}{*}{$\mathrm{MDI}<70$} & Duration of $\mathrm{O}_{2}$ requirement & $10.02(10.005-10.040)$ & .010 \\
\hline & Prenatal steroids & $0.06(0.005-0.747)$ & .028 \\
\hline & History of sepsis & 3.72 (10.0337-13.363) & .044 \\
\hline \multirow[t]{2}{*}{ Major neurologic outcomes } & AED medication & $6.96(1.274-37.988)$ & .025 \\
\hline & History of sepsis & $2.51(0.970-6.485)$ & .058 \\
\hline
\end{tabular}

\begin{tabular}{|c|c|c|c|}
\hline Measurements & Outcomes & OR $(95 \% \mathrm{Cl})$ & $P$ Value \\
\hline \multirow[t]{3}{*}{ TCD } & $\mathrm{PDI}<70$ & $0.780(0.662-0.919)$ & .003 \\
\hline & $\mathrm{MDI}<70$ & $0.785(0.665-0.927)$ & .004 \\
\hline & Major neurologic disability & $0.815(0.704-0.944)$ & .006 \\
\hline \multirow{2}{*}{ Corpus callosal length } & $\mathrm{MDI}<70$ & $0.876(0.768-0.998)$ & .047 \\
\hline & High-risk or diagnosed CP & $0.915(0.838-0.999)$ & .049 \\
\hline
\end{tabular}

Note:-CP indicates cerebral palsy.

Table 4: Perinatal factors associated with MRI measurements on multivariate analysis

\begin{tabular}{|c|c|c|c|}
\hline \multirow[b]{2}{*}{ Measurements } & \multicolumn{3}{|c|}{ Estimated Regression Coefficient } \\
\hline & Perinatal Factors & $(95 \% \mathrm{Cl})$ & $P$ Value \\
\hline \multirow[t]{4}{*}{ TCD } & Birth weight & $0.005[0.001,0.010]$ & .028 \\
\hline & Presence of BPD & $-2.358[-40.025,-0.692]$ & .007 \\
\hline & AED medication & $-3.347[-5.840,-0.853]$ & .010 \\
\hline & History of sepsis & $-1.642[-3.137,-0.146]$ & .034 \\
\hline \multirow[t]{3}{*}{ Corpus callosal length } & $\mathrm{HC}$ when MRI was taken & $3.947[1.915,5.978]$ & $<.001$ \\
\hline & Prenatal steroids & $10.141[40.017,16.264]$ & .002 \\
\hline & AED medication & $-8.215[-12.641,-3.790]$ & $<.001$ \\
\hline
\end{tabular}

Note:- $-\mathrm{HC}$ indicates head circumference; BPD, bronchopulmonary dysplasia.

an effect on the area of the cerebellum, have been reported. Sepsis, an independent risk factor for a poor neurologic outcome, ${ }^{25,34,38}$ could have exerted a detrimental effect on the growth of the cerebellum by diffuse white matter injury, ${ }^{24}$ bacterial products and cytokines, ${ }^{39,40}$ arterial hypotension, and combined cerebral ischemia. ${ }^{25}$ Bronchopulmonary dysplasia, a known risk factor for neurodevelopmental impairment, has also been reported to exert an effect on the granular cells of the cerebellum, as shown in a baboon model. ${ }^{33}$ In the present study, however, bronchopulmonary dysplasia alone was not associated with severe cognitive and motor deficits, though the duration of $\mathrm{O}_{2}$ requirement, which may have included a period of hyperoxia and hypoxia, was associated with poor cognitive and motor outcomes. Reports have shown that the use of either a high oxygen concentration, which affects the inner granular cell and Purkinje cell layer, ${ }^{33}$ or a hypoxic insult, which affects neuronal migration, ${ }^{41}$ could influence the growth of the developing human cerebellum.

A premature transition from intrauterine to extrauterine life $\mathrm{e}^{10}$ and stress or damage in the neonatal period could affect the development of the corpus callosum. The corpus callosum is known to have an intrinsic vulnerability to hypoxic-ischemic damage and hemorrhage. ${ }^{2,14}$ A decreased number or diameter of axons and myelin loss was observed in preterm infants with hypoxia or ischemia $^{42}$ that could be explained with necrosis, apoptosis, astrogliosis, and microgliosis as well as injury of premyelinating oligodendrocytes in white matter, including the corpus callosum. ${ }^{7,43}$ In the development of the corpus callosum, the corpus callosum expands in the craniocaudal direction: genu first and then body to splenium. ${ }^{12}$ Thus, the development of the posterior part is an ongoing process that continues through the neonatal period after preterm birth, and an altered development of the corpus callosum such as a shortening and/or thinning persists into childhood. ${ }^{14}$ We assumed that the underdevelopment of the posterior part of the corpus callosum would result in a shorter length of the corpus callosum as well as a thinning of the splenium. Our attempt to measure the thickness of the corpus callosum was hampered by a poor consistency in the measurements (ICC $=0.133-0.418$ in interobserver variability, ICC $=0.003$ 0.367 in intraobserver variability). Reports have shown a positive relationship between both the corpus callosal size and total white matter volume and a decreased area of the posterior or midposterior region corresponding to the splenium and poor verbal skill in preterm males. ${ }^{14}$ In our study, a short corpus callosal length was associated in univariate analysis with high-risk or diagnosed cerebral palsy and an MDI $<70$.

In contrast to the study of Wood et $\mathrm{al},{ }^{44}$ which reported a relationship between the administration of antenatal steroids and a lower MDI, antenatal steroid showed a protective effect on the growth of the corpus callosum in our study (Table 4), in accordance with the protective effect of antenatal steroids on white matter injury in very low-birth-weight infants reported by Leviton et $\mathrm{al}^{23}$ and Agarwal et al. ${ }^{22}$ The effect of seizures, as evidenced by the use of AEDs in our study, might have caused the reduction in the corpus callosal volume, especially in the posterior region, as reported by Hermann et al. ${ }^{45}$

There are limitations that must be addressed regarding the present study. We did not examine the association of the white or gray matter abnormalities, such as hemorrhage or leukomalacia, and other signal changes with brain measurements. The other limitation includes the short-term follow-up period and a lack of control group. Further research is required to determine whether the changes in brain structures in very preterm infants would persist into later life.

\section{CONCLUSIONS}

In this study, we were able to elucidate the usefulness of the axial measurement of the TCD and the length of the corpus callosum taken from brain MR imaging at term-corrected ages in predicting long-term neurologic outcome. Various perinatal factors, such as a lower birth weight, use of AEDs, sepsis, bronchopulmonary dysplasia, and a smaller head circumference, some of which are independently associated with poor cognitive and motor skills later in life, could affect the development of the cerebellum and corpus callosum during the most vulnerable period in NICU hospitalization. 


\section{REFERENCES}

1. Inder TE, Warfield SK, Wang H, et al. Abnormal cerebral structure is present at term in premature infants. Pediatrics 2005;115:286-94

2. Back SA, Luo NL, Borenstein NS, et al. Late oligodendrocyte progenitors coincide with the developmental window of vulnerability for human perinatal white matter injury. J Neurosci 2001;21:1302-12

3. Neubauer AP, Voss W, Kattner E. Outcome of extremely low birth weight survivors at school age: the influence of perinatal parameters on neurodevelopment. Eur J Pediatr 2008;167:87-95

4. Shah DK, Doyle LW, Anderson PJ, et al. Adverse neurodevelopment in preterm infants with postnatal sepsis or necrotizing enterocolitis is mediated by white matter abnormalities on magnetic resonance imaging at term. J Pediatr 2008;153:170-75.e1

5. Wood NS, Marlow N, Costeloe K, et al. Neurologic and developmental disability after extremely preterm birth: EPICure Study Group. N Engl J Med 2000;343:378-84

6. Armstrong DL, Bagnall C, Harding JE, et al. Measurement of the subarachnoid space by ultrasound in preterm infants. Arch Dis Child Fetal Neonatal Ed 2002;86:F124-26

7. Volpe JJ. Brain injury in premature infants: a complex amalgam of destructive and developmental disturbances. Lancet Neurol 2009;8:110-24

8. Volpe JJ. Cerebellum of the premature infant: rapidly developing, vulnerable, clinically important. J Child Neurol 2009;24:1085-104

9. Sauerwein HC, Lassonde M. Cognitive and sensori-motor functioning in the absence of the corpus callosum: neuropsychological studies in callosal agenesis and callosotomized patients. Behav Brain Res 1994;64:229-40

10. Peterson BS, Anderson AW, Ehrenkranz R, et al. Regional brain volumes and their later neurodevelopmental correlates in term and preterm infants. Pediatrics 2003;111:939-48

11. Horsch S, Muentjes C, Franz A, et al. Ultrasound diagnosis of brain atrophy is related to neurodevelopmental outcome in preterm infants. Acta Paediatr 2005;94:1815-21

12. Rademaker KJ, Lam JN, Van Haastert IC, et al. Larger corpus callosum size with better motor performance in prematurely born children. Semin Perinatol 2004;28:279-87

13. Iai $\mathrm{M}$, Tanabe $\mathrm{Y}$, Goto $\mathrm{M}$, et al. A comparative magnetic resonance imaging study of the corpus callosum in neurologically normal children and children with spastic diplegia. Acta Paediatr 1994;83:1086-90

14. Nosarti C, Rushe TM, Woodruff PW, et al. Corpus callosum size and very preterm birth: relationship to neuropsychological outcome. Brain 2004;127:2080-89

15. Dyet LE, Kennea N, Counsell SJ, et al. Natural history of brain lesions in extremely preterm infants studied with serial magnetic resonance imaging from birth and neurodevelopmental assessment. Pediatrics 2006;118:536-48

16. Nguyen The Tich S, Anderson PJ, Shimony JS, et al. A novel quantitative simple brain metric using MR imaging for preterm infants. AJNR Am J Neuroradiol 2009;30:125-31

17. Lind A, Parkkola R, Lehtonen L, et al. Associations between regional brain volumes at term-equivalent age and development at 2 years of age in preterm children. Pediatr Radiol 2011;41:953-61

18. Effect of corticosteroids for fetal maturation on perinatal outcomes. NIH Consensus Statement 1994;12:1-24

19. Hamrick SE, Hansmann G. Patent ductus arteriosus of the preterm infant. Pediatrics 2010;125:1020-30

20. Early Treatment for Retinopathy of Prematurity Cooperative Group. Revised indications for the treatment of retinopathy of prematurity: results of the Early Treatment for Retinopathy of Prematurity Randomized Trial. Arch Ophthalmol 2003;121:1684-94

21. Im KC, Choi IS, Ryu JS, et al. PET/CT fusion viewing software for use with picture archiving and communication systems. J Digit Imaging 2010;23:732-43

22. Agarwal R, Chiswick ML, Rimmer S, et al. Antenatal steroids are associated with a reduction in the incidence of cerebral white matter lesions in very low birthweight infants. Arch Dis Child Fetal Neonatal Ed 2002;86:F96-101
23. Leviton A, Dammann O, Allred EN, et al. Antenatal corticosteroids and cranial ultrasonographic abnormalities. Am J Obstet Gynecol 1999;181:1007-17

24. Stoll BJ, Hansen NI, Adams-Chapman I, et al. Neurodevelopmental and growth impairment among extremely low-birth-weight infants with neonatal infection. JAMA 2004;292:2357-65

25. Schlapbach LJ, Aebischer M, Adams M, et al. Impact of sepsis on neurodevelopmental outcome in a Swiss national cohort of extremely premature infants. Pediatrics 2012;128:e348-57

26. Hayashi-Kurahashi N, Kidokoro H, Kubota T, et al. EEG for predicting early neurodevelopment in preterm infants: an observational cohort study. Pediatrics 2012;130:e891-97

27. Sutton PS, Darmstadt GL. Preterm birth and neurodevelopment: a review of outcomes and recommendations for early identification and cost-effective interventions. J Trop Pediatr 2013;59:258-65

28. Harijan P, Beer C, Glazebrook C, et al. Predicting developmental outcomes in very preterm infants: validity of a neonatal neurobehavioral assessment. Acta Paediatrica 2012;101:e275-81

29. Singh P, Davies TI. A comparison of cephalometric measurements: a picture archiving and communication system versus the handtracing method: a preliminary study. Eur J Orthod 2011;33:350-53

30. Monsky WL, Raptopoulos V, Keogan MT, et al. Reproducibility of linear tumor measurements using PACS: comparison of caliper method with edge-tracing method. Eur Radiol 2004;14:519-25

31. Khakharia S, Bigman D, Fragomen AT, et al. Comparison of PACS and hard-copy 51-inch radiographs for measuring leg length and deformity. Clin Orthop Relat Res 2011;469:244-50

32. Limperopoulos C, Soul JS, Gauvreau K, et al. Late gestation cerebellar growth is rapid and impeded by premature birth. Pediatrics 2005; 115:688-95

33. Rees SM, Loeliger MM, Munro KM, et al. Cerebellar development in a baboon model of preterm delivery: impact of specific ventilatory regimes. J Neuropathol Exp Neurol 2009;68:605-15

34. Tich SNT, Anderson PJ, Hunt RW, et al. Neurodevelopmental and perinatal correlates of simple brain metrics in very preterm infants. Arch Pediatr Adolesc Med 2011;165:216-22

35. Ney GC, Lantos G, Barr WB, et al. Cerebellar atrophy in patients with long-term phenytoin exposure and epilepsy. Arch Neurol 1994;51:767-71

36. De Marcos FA, Ghizoni E, Kobayashi E, et al. Cerebellar volume and long-term use of phenytoin. Seizure 2003;12:312-15

37. Hannah RS, Roth SH, Spira AW. Effect of phenobarbital on Purkinje cell growth patterns in the rat cerebellum. Exp Neurol 1988;100: 354-64

38. Shah DK, Anderson PJ, Carlin JB, et al. Reduction in cerebellar volumes in preterm infants: relationship to white matter injury and neurodevelopment at two years of age. Pediatr Res 2006;60:97-102

39. Schlapbach LJ, Aebischer M, Adams M, et al. Impact of sepsis on neurodevelopmental outcome in a Swiss national cohort of extremely premature infants. Pediatrics 2011;128:e348-57

40. Wu YW, Colford JM. Chorioamnionitis as a risk factor for cerebral palsy. JAMA 2000;284:1417-24

41. Rees S, Stringer M, Just $\mathrm{Y}$, et al. The vulnerability of the fetal sheep brain to hypoxemia at mid-gestation. Dev Brain Res 1997;103:103-18

42. Nagy Z, Westerberg H, Skare S, et al. Preterm children have disturbances of white matter at 11 years of age as shown by diffusion tensor imaging. Pediatr Res 2003;54:672-79

43. Tekkok SB, Goldberg MP. Ampa/kainate receptor activation mediates hypoxic oligodendrocyte death and axonal injury in cerebral white matter. J Neurosci 2001;21:4237-48

44. Wood NS, Costeloe K, Gibson AT, et al. The EPICure study: associations and antecedents of neurological and developmental disability at 30 months of age following extremely preterm birth. Arch Dis Child Fetal Neonatal Ed 2005;90:F134-40

45. Hermann B, Hansen R, Seidenberg M, et al. Neurodevelopmental vulnerability of the corpus callosum to childhood onset localization-related epilepsy. NeuroImage 2003;18:284-92 
D ue to a print production error, Fig 1 in the article "Brain MRI Measurements at a Term-Equivalent Age and Their Relationship to Neurodevelopmental Outcomes” by H.W. Park, H.-K. Yoon, S.B. Han, B.S. Lee, I.Y. Sung, K.S. Kim, and E.A. Kim [AJNR Am J Neuroradiol 2014;35:599-603] did not contain tabular material that was part of the illustration. The correct image is displayed here.

http://dx.doi.org/10.3174/ajnr.A3963
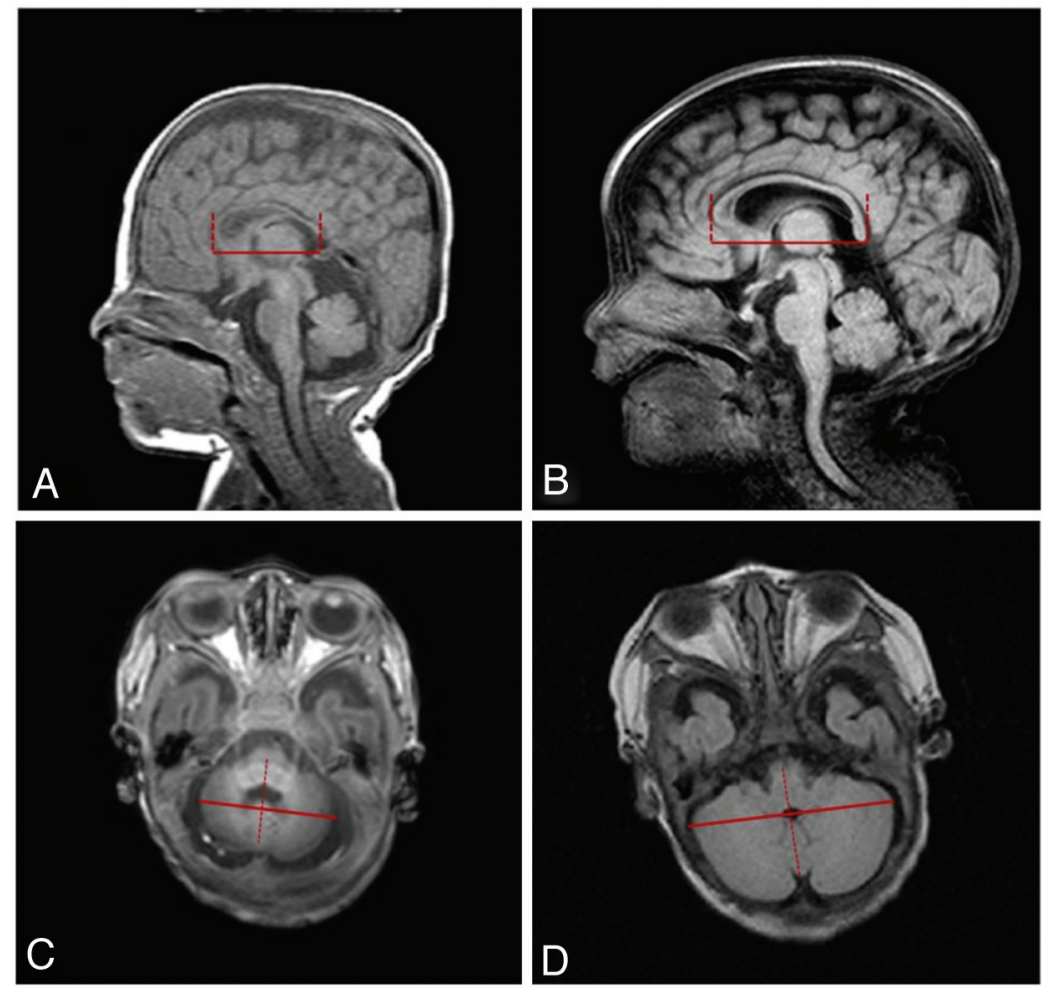

\begin{tabular}{lcc}
\hline Measurements & Intra-observer ICC [CI] & Inter-observer ICC [CI] \\
\hline TCD & $0.895[0.831-0.933]$ & $0.679[0.479-0.811]$ \\
Length of corpus callosum & $0.564[0.404-0.690]$ & $0.808[0.595-0.903]$ \\
\hline
\end{tabular}

FIG 1. Linear measurements of anteroposterior length of corpus callosum ( $A$ and $B$ ) and transcerebellar diameter $(C$ and $D)$ and intraclass correlation coefficients (ICCs) for interobserver and intraobserver reliability. A, Short anteroposterior length of corpus callosum (34.1 mm); $B$, longer anteroposterior length of corpus callosum ( $44.4 \mathrm{~mm})$; $C$, short transcerebellar diameter $(36.2 \mathrm{~mm})$; $D$, longer transcerebellar diameter (58.4 $\mathrm{mm})$. 